\title{
Does Money Matter? Relationship between Household Income and Mortality after Trauma
}

Bernardino C Branco ${ }^{1}$, Matthew Mobily ${ }^{2}$, Peter Rhee ${ }^{3}$, Julie L Wynne ${ }^{4}$, Randall S Friese ${ }^{5}$, Narong Kulvatunyou ${ }^{6}$, Bellal Joseph ${ }^{7}$, Andrew L Tang ${ }^{8}$, Terence O'Keeffe ${ }^{9}$

\begin{abstract}
Background: Previous studies have demonstrated an association between lack of insurance and outcomes after trauma. However, it is not clear if this is merely a surrogate for socioeconomic status. The purpose of this study is to investigate the relationship between household income and mortality among injured patients.

Methods: The Arizona Inpatient State Database was used to identify all trauma patients over a representative 1-year period. Demographics, clinical data, and outcomes were extracted. Median household income (MHI) for patients' domiciliary zip code was extracted. Patients were divided into four quartiles according to $\mathrm{MHI}$ (lowest, low, high, and highest). The standard statistical analysis was used to compare groups.

Results: A total of 58,743 were available for analysis (lowest: 27.6\%; low: 25.9\%; high: 26.3\%; and highest: 20.2\%). There was a decrease in the proportion of males as MHI increased (lowest: $53.4 \%$, low: $48.8 \%$, high: $49.2 \%$, and highest: $48.7 \%, p<0.001$ ). Similarly, there was a decrease in the proportion of Hispanics and Native Americans (Hispanics: lowest: 23.6\%, low: 14.9\%, high: 12.9\%, and highest: 5.9\%, $p<0.001$; Native Americans: lowest: $10.8 \%$, low: $2.5 \%$, high: $2.9 \%$, and highest: $0.8 \%, p<0.001$ ). There was also a decrease in the incidence of penetrating trauma as MHI increased (lowest: 9.6\%, low: 8.4\%, high: 7.6\%, and highest: $6.6 \%, p<0.001$ ), in particular for gunshot wound (GSWs) (lowest: $5.7 \%$, low: $5.4 \%$, high: $5.0 \%$, highest: $4.5 \%, p<0.001)$. After adjustment for demographics and clinical data, when outcomes were analyzed, there was a stepwise decrease in mortality as MHI increased (Log rank $=0.002$ ).
\end{abstract}

Conclusion: Patients with low MHI have a higher adjusted mortality rate after trauma. To address health-related disparities, socioeconomic disparities must be ameliorated. Further evaluation of these results is warranted.

Keywords: Household income, Mortality, Outcomes, Trauma.

Panamerican Journal of Trauma, Critical Care \& Emergency Surgery (2019): 10.5005/jp-journals-10030-1245

\section{Resumo}

Antecedentes: Estudos anteriores demonstraram uma associação entre não ter seguro médico e as consequência (outcome) após trauma. No entanto, não está claro se não ter seguro médico é apenas um substituto para o status socioeconômico. O objetivo deste estudo é investigar a relação entre renda familiar e mortalidade entre pacientes traumatizados.

Métodos: O Banco de Dados dos Paciente Internados no Estado do Arizona (EUA) foi utilizado para identificar todos os pacientes traumatizados durante o período de 1 ano. Demografia, dados clínicos e resultados foram extraídos. A renda média familiar (RFM) para o código postal domiciliar dos pacientes foi extraída. Os pacientes foram divididos em quatro quartis de acordo com o RFM (menor, baixo, alto e mais alto). A análise estatística padrão foi usada para comparar os grupos.

Resultados: um total de 58.743 estavam disponíveis para análise (RFM menor: 27,6\%; baixo: 25,9\%; alta: 26,3\%; e maior: 20,2\%). Houve uma diminuição na proporção de homens à medida que o RFM aumentou (menor: 53,4\%, baixo: 48,8\%, alto: 49,2\% e maior: 48,7\%, $p<0,001$ ). Da mesma forma, houve uma diminuição na proporção de hispânicos e nativos americanos (hispânicos: RFM mais baixo: 23,6\%, baixo: 14,9\%, alto: $12,9 \%$ e mais alto: $5,9 \%, p<0,001$; nativos americanos: RFM mais baixo: $10,8 \%$, baixo: $2,5 \%$, alto: $2,9 \%$ e mais alto: $0,8 \%, p<0,001$ ). Houve também uma diminuição na incidência de trauma penetrante à medida que o RFM aumentou (menor: 9,6\%, baixo: 8,4\%, alto: 7,6\% e mais alto: 6,6\%, $p<0,001$ ), em especial para ferimentos por projétil de arma de fogo (bala) (RFM menor: 5,7\%, baixo: 5,4\%, alto: 5,0\%, mais alto: 4,5\%, $p<0,001$ ). Após o ajuste dos dados demográficos e clínicos, quando os resultados foram analisados, houve uma diminuição gradual da mortalidade à medida que o RFM aumentou (log rank =0,002).

Conclusões: Pacientes com baixa RFM apresentam maior taxa de mortalidade ajustada após trauma. Para tratar das disparidades relacionadas à saúde, as disparidades socioeconômicas precisam também ser atenuadas. É necessária uma avaliação mais aprofundada desses resultados.

Palabras clave: Mortalidade, Renda Familiar, Resultados, Trauma.

\section{INTRODUCTION}

Despite advancements in injury prevention and management, trauma remains one of the leading causes of death for every age group and is the leading cause of death for those aged $1-44$ years. ${ }^{1}$ For those surviving to hospital admission, several population-based studies have demonstrated that uninsured patients are more likely to have worse outcomes. ${ }^{2-18}$ These patients may be faced with disparities in triaging, diagnostic work-up, hospital admission, implementation of a treatment plan, and many other unmeasurable and immeasurable variables. The added mortality risk may be as high as $52 \%$ when adjusted
${ }^{1-9}$ Department of Surgery, University of Arizona, Tucson, Arizona, USA Corresponding Author: Matthew Mobily, Department of Surgery, University of Arizona, Tucson, Arizona, USA, Phone: +1 520-626-5555, e-mail: mobily@surgery.arizona.edu

How to cite this article: Branco BC, Mobily M, et al. Does Money Matter? Relationship between Household Income and Mortality after Trauma. Panam J Trauma Crit Care Emerg Surg 2019;8(2):91-95.

Source of support: Nil

Conflict of interest: None

() The Author(s). 2019 Open Access This article is distributed under the terms of the Creative Commons Attribution 4.0 International License (https://creativecommons. org/licenses/by-nc/4.0/), which permits unrestricted use, distribution, and non-commercial reproduction in any medium, provided you give appropriate credit to the original author(s) and the source, provide a link to the Creative Commons license, and indicate if changes were made. The Creative Commons Public Domain Dedication waiver (http://creativecommons.org/publicdomain/zero/1.0/) applies to the data made available in this article, unless otherwise stated. 
for differences in demographics, comorbidities, injury mechanism, and severity. ${ }^{13}$ It is unknown, however, whether the absence of insurance is merely a surrogate marker for socioeconomic status.

A more complete understanding of the impact of socioeconomic status on mortality after trauma is particularly important given the current era of job displacement, steady unemployment rates, decreasing labor productivity growth, and increasing social inequality. In the United States, income data indicate that the middle class has seen far slower income growth than the top $1 \%$ since 1980 . Over the last 25 years, the mean after-tax income of the top $1 \%$ increased by an inflation adjusted $176 \%$ vs $69 \%$ for the top $20 \%$ overall. The fourth quintile saw its mean net income increase by $29 \%$, the middle-income quintile by $21 \%$, the second quintile by $17 \%$, and the bottom quintile by a mere $6 \% .{ }^{19}$ From a healthcare standpoint, the US Congressional Budget Office estimates that approximately 30 million of the current pool of 50 million uninsured US residents will continue without insurance despite full implementation of the Patient Protection and Affordable Care Act, also known as Obamacare. ${ }^{20}$

The purpose of our study is to investigate the relationship between household incomes, which we used as a surrogate marker of socioeconomic status, and mortality rates among injured patients. We hypothesized that patients of lower household income would have higher adjusted mortality risk after trauma.

\section{Methods}

For this retrospective study, the study population was extracted from the Arizona State Inpatient Database (SID) which was compiled as a part of the Healthcare Cost and Utilization Project (HCUP). This database contains demographics, clinical data, and outcomes from inpatient discharge abstracts within the state of Arizona. The Arizona SID was queried to identify all trauma patients during the year of 2010 (The International Classification of Diseases, 9th Revision, Clinical Modification, ICD-9-CM external cause of injury codes [E codes], E800-E999).

Patient variables extracted included age, gender, ethnicity, marital status, patient zip code, insurance status, $\mathrm{MHI}$, comorbidities, diagnosis and procedures ICD-9-CM codes, and outcomes. The primary outcome measure of this study was in-hospital mortality. Secondary outcome measures were hospital length of stay (HLOS) and total hospital charges. MHI was defined as the amount in US dollars (\$) that divides the income distribution for a specific domiciliary zip code into equal segments. Patients were divided into four quartiles according to $\mathrm{MHI}$ (lowest, low, high, and highest).

These four groups were compared for differences in demographics, comorbidities, and clinical data using standard statistical analyses. A Chi-square test was used to compare proportions, and analysis of variance (ANOVA) was used to compare means. For the analysis of outcomes, binary logistic regression and analysis of covariance (ANCOVA) were used to control for confounders that were significantly different at the $p<0.05$ level between groups. Adjusted odds ratio (OR) or mean difference (MD) and $95 \%$ confidence intervals $(\mathrm{Cl})$ were calculated for each group. A Cox regression analysis was used to evaluate the association between $\mathrm{MHI}$ and mortality. In addition, to identify if $\mathrm{MHI}$ was independently associated with mortality, a Cox proportional hazard regression model was performed including all factors that had a $p$ value $<0.2$ from the univariate analysis.

The summary data are presented as a raw percentage or mean \pm SD. Results were considered statistically significant for $p$ values $<0.05$. Data were analyzed using the SPSS for Windows, version 19.0 (SPSS, Chicago, Illinois).

\section{Results}

During the year 2010, a total of 790,492 patients were included in the Arizona SID. Of those, 62,133 (7.9\%) were trauma patients admitted to 104 hospitals in the state of Arizona. After the exclusion of 3,390 (5.5\%) with missing $\mathrm{MHI}, 58,743$ (94.5\%) were available for analysis [lowest MHI: 16,194 (27.6\%) patients; low MHI: 15,233 (25.9\%) patients; high MHI: 15,477 (26.3\%) patients; highest MHI: 11,839 (20.2\%) patients] (Flowchart 1).

Overall, patients of the lowest MHI were significantly younger $(52.9 \pm 25.5$ years for the lowest MHI vs $57.0 \pm 25.8$ years for low $\mathrm{MHI}$ vs $57.2 \pm 25.6$ years for high $\mathrm{MHI}$ vs $58.0 \pm 25.6$ years for the highest $\mathrm{MHI}, p<0.001)$ and more likely to be male $(53.4 \%$ for lowest vs $48.8 \%$ for low vs $49.2 \%$ for high vs $48.7 \%$ for the highest, $p<0.001$ ). The lowest MHI group was significantly more likely to be uninsured (14.4\% for the lowest vs $10.5 \%$ for low vs $10.6 \%$ for high vs $9.9 \%$ for the highest, $p<0.001)$ and single $(47.5 \%$ for the lowest vs $37.3 \%$ for low vs $35.7 \%$ for high vs $30.1 \%$ for the highest, $p<0.001)$. Patients of the lowest MHI were less likely to be Caucasian $(60.3 \%$ for the lowest vs $78.2 \%$ for low vs $80.3 \%$ for high vs $89.7 \%$ for the highest, $p<0.001)$ and more likely to be Native American (10.8\% for the lowest vs $2.5 \%$ for low vs $2.9 \%$ for high vs $0.8 \%$ for the lowest, $p<0.001)$; they were also more likely to have comorbidities such as chronic ethanol (ETOH) abuse (164.2\% for the lowest vs $10.1 \%$ for low vs $9.0 \%$ for high vs $7.8 \%$ for the highest, $p<0.001$ ) and diabetes mellitus (DM) $(19.6 \%$ for the lowest vs $18.3 \%$ for low vs $17.6 \%$ for high vs $15.4 \%$ for the highest, $p<0.001$ ) (Table 1 ).

When clinical data were analyzed, patients of the lowest $\mathrm{MHI}$ had higher incidence of penetrating injuries $(9.6 \%$ for the lowest vs $8.4 \%$ for low vs $7.6 \%$ for high vs $6.6 \%$ for the highest, $p<0.001)$, in particular GSWs (5.7\% for the lowest vs $5.4 \%$ for low vs $5.0 \%$ for high vs $4.5 \%$ for the highest, $p<0.001$ ) (Table 1 ).

After adjusting for significant differences in demographics and clinical data using logistic regression analysis, patients of the lowest $\mathrm{MHI}$ had higher in-hospital mortality rates $(2.0 \%$ for the lowest vs $1.8 \%$ for low vs $1.4 \%$ for high vs $1.6 \%$ for the highest, Adj. $p=0.005$ ). (Table 2). No significant differences in HLOS could be demonstrated. When hospital charges were analyzed, patients of low MHI had lower total hospital charges ( $p=0.005$ ) (Table 2).

Cox proportional time to event analysis revealed late separation of the 30-day survival curves for the highest and high $\mathrm{MHI}$ relative to low and the lowest MHI (Fig. 1).

Cox proportional hazard regression was then used to determine the independent risk factors associated with mortality. After

Flowchart 1: Study outline

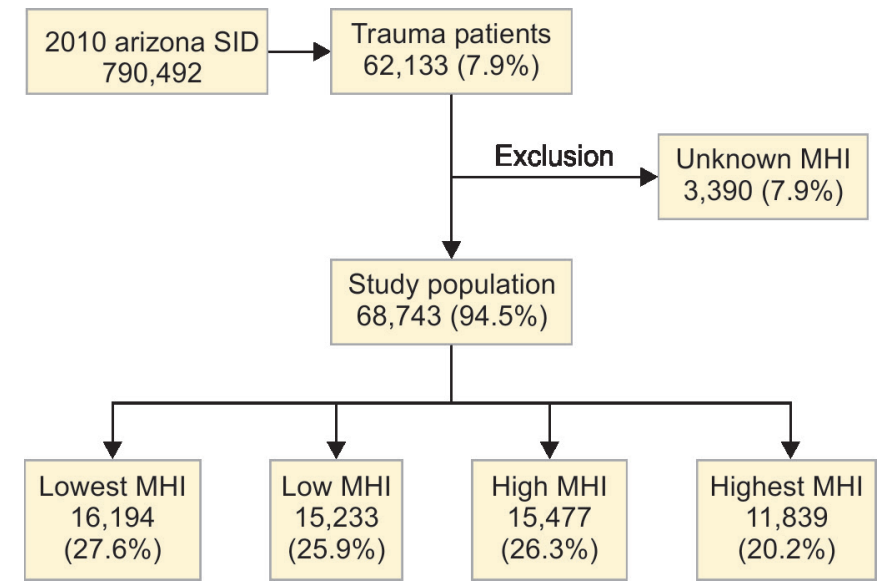


Table 1: Demographic and clinical data of patient groups

\begin{tabular}{|c|c|c|c|c|c|}
\hline HTN (\%) & $41.9 \%(6,757)$ & $45.9 \%(8,768)$ & $46.0 \%(5,497)$ & $45.3 \%(5,245)$ & $<0.001^{*}$ \\
\hline \multicolumn{6}{|l|}{ Clinical data } \\
\hline Penetrating (\%) & $9.6 \%(1,555)$ & $8.4 \%(1,598)$ & $7.6 \%(908)$ & $6.6 \%(759)$ & $<0.001^{*}$ \\
\hline - SW (\%) & $3.9 \%(631)$ & $3.0 \%(566)$ & $2.6 \%(313)$ & $2.0 \%(233)$ & $<0.001^{*}$ \\
\hline - GSW (\%) & $5.7 \%(924)$ & $5.4 \%(1,032)$ & $5.0 \%(595)$ & $4.5 \%(526)$ & $<0.001^{*}$ \\
\hline Intracranial injury (\%) & $4.9 \%(795)$ & $4.5 \%(851)$ & $4.5 \%(537)$ & $4.0 \%(464)$ & $0.004^{*}$ \\
\hline Torso (\%) & $5.7 \%(925)$ & $5.2 \%(998)$ & $6.2 \%(741)$ & $5.8 \%(674)$ & $0.003^{*}$ \\
\hline Major vessels (\%) & $1.5 \%(237)$ & $1.3 \%(253)$ & $1.1 \%(126)$ & $0.9 \%(103)$ & $<0.001^{*}$ \\
\hline Musculoskeletal (\%) & $16.5 \%(2,663)$ & $15.5 \%(2,961)$ & $16.5 \%(1966)$ & $16.9 \%(1,953)$ & $0.006^{*}$ \\
\hline
\end{tabular}

The $p$ values for categorical variables were derived from Chi-square test; $p$ values for continuous variables were derived from ANOVA ${ }^{*} p$ values are significantly different $(p<0.05)$

SD, standard deviation; HTN, systemic hypertension; SW, stab wound

Table 2: Outcomes

\begin{tabular}{|c|c|c|c|c|c|}
\hline & $\begin{array}{l}\text { Lowest MHI } \\
(n=16,194)\end{array}$ & $\begin{array}{l}\text { Low MHI } \\
(n=15,233)\end{array}$ & $\begin{array}{l}\text { High MHI } \\
(n=15,477)\end{array}$ & $\begin{array}{l}\text { Highest MHI } \\
(n=11,839)\end{array}$ & Adj.p \\
\hline Mortality (\%) & $2.0 \%(315)$ & $1.8 \%(334)$ & $1.4 \%(164)$ & $1.6 \%(189)$ & $0.005^{*}$ \\
\hline & Mean \pm SD [median], (range) & & Mean \pm SD [median], (range) & Mean \pm SD [median], (range) & \\
\hline Hospital days & $5.2 \pm 7.1$ & $5.1 \pm 6.2$ & $4.9 \pm 6.1$ & $5.0 \pm 6.9$ & 0.143 \\
\hline Hospital charges (\$) & $47,446 \pm 68,562$ & $45,913 \pm 63,671$ & $49,010 \pm 67,221$ & $47,826 \pm 65,673$ & $0.005^{*}$ \\
\hline
\end{tabular}

The $p$ values were derived from logistic regression for mortality; and from ANCOVA for hospital days and charges

The $p$ values were obtained after adjustment for age, gender, marital status, ethnicity, comorbidities, injury mechanism, and injuries sustained ${ }^{*} p$ values are significantly different $(p<0.05)$



Fig. 1: Cox regression time to event analysis for in-hospital mortality by $\mathrm{MHI}$ controlling for differences in age, gender, insurance, marital status, ethnicity, comorbidities, and injury mechanism, there was an association between $\mathrm{MHI}$ and mortality risk (Table 3 ).

Table 4 compares the mortality between insured and uninsured patients divided by MHI. Interestingly, no significant difference in mortality between insured and uninsured patients could be detected across all MHI groups.

\section{Discussion}

The present study demonstrates that socioeconomic status plays a major role in explaining health-related disparities in outcomes after trauma, more than insurance status per se. Insurance status has been a well-documented risk factor for adverse outcomes in the medical literature. The lack of insurance has been associated with severe disparities in access to healthcare including screening, hospital admission, management/treatment, and outcomes. ${ }^{3-5}$ A large population-based study from Virginia demonstrated that uninsured patients were two times less

Table 3: Cox proportional hazard regression model with mortality as the dependent variable

\begin{tabular}{llllll}
\hline Step & Variable & Mortality (\%) & $R^{2}$ & Adj. OR (95\% Cl) & Adj.p \\
\hline 1 & Age $\geq 55$ years & 2.2 & 0.02 & $2.3(2.0,2.6)$ & $1.6(1.4,1.8)$ \\
2 & Male & 2.0 & 0.01 & & $<.001^{*}$ \\
& MHI & & & $1.4(1.1,1.6)$ & $0.001^{*}$ \\
3 & Highest & 1.6 & 0.03 & $1.2(0.9,1.4)$ & $0.001^{*}$ \\
4 & High & 1.4 & & $0.8(0.7,1.1)$ & 0.112 \\
5 & Low & 1.8 & & - & - \\
\hline
\end{tabular}

Variables entered in the model: age, gender, insurance and marital status, ethnicity, comorbidities, and injury mechanism

A total of $57,642(98.1 \%)$ subjects with complete data were included in the model

${ }^{*} p$ values are significantly different $(p<0.05)$

$\mathrm{OR}$, odds ratio; $\mathrm{Cl}$, confidence interval 
Does Money Matter? Relationship between Household Income and Mortality after Trauma

Table 4: Mortality by MHI and insurance status

\begin{tabular}{llllll}
\hline & Lowest MHI $(n=16,194)$ & Low MHI $(n=15,233)$ & High MHI $(n=15,477)$ & Highest MHI $(n=11,839)$ & Adj. $p$ \\
\hline Insured, \% & $2.0 \%$ & $1.8 \%$ & $1.4 \%$ & $1.7 \%$ & $0.002^{*}$ \\
Uninsured, \% & $2.3 \%$ & $1.6 \%$ & $0.8 \%$ & $1.8 \%$ & $0.023^{*}$ \\
Adj.p & 0.428 & 0.329 & 0.131 & 0.687 & \\
\hline
\end{tabular}

$p$ for mortality was derived from logistic regression

Adjusted $p$ after adjustment for age, gender, insurance, marital status, ethnicity, comorbidities, and injury mechanism and type

*Significantly different $(p<0.05)$

Adj., adjusted for

likely to undergo screening colonoscopy compared with insured patients of similar colon cancer risk. ${ }^{5}$ Another study targeting specifically women with breast cancer found that uninsured patients were more likely to present with advanced-stage tumors and to undergo operative interventions such as breast reconstruction therapy less often. ${ }^{3}$

In the field of trauma and acute care surgery, under the Emergency Medical Treatment and Active Labor Act, all hospitals are required to provide emergency care regardless of patient's ability to pay. Yet, studies continue to demonstrate that uninsured patients are still more likely to die after trauma. ${ }^{8-10,13,16,18}$ They are also less likely to be admitted to the hospital, more likely receive fewer services during their admission such as diagnostic tests when compared to insured trauma patients. ${ }^{2,6,9,15}$

In one of the largest examinations to date, Rosen et al. from the Center for Surgery and Public Health at Harvard Medical School reported the magnitude of the accidental cost of being uninsured. They used the National Trauma Databank version 7.0 (2002-2006) including over 600,000 patients from 900 US trauma centers who sustained injuries. The crude analysis demonstrated a higher mortality for uninsured patients $(5.7 \%$ for uninsured vs $3.3 \%$ commercial vs $2.9 \%$ Managed Care Organization (MCO) vs $6.7 \%$ Medicare vs 3.7\% Medicaid, $p<0.001$ ). Those results held true after adjustments for demographics, comorbidities, and clinical data. Subgroup analysis demonstrated that uninsured patients with one or more comorbidities or those who sustained traumatic brain injury are at highest risk for death. ${ }^{13}$ The adverse effects of the lack of insurance on trauma patient outcomes have been demonstrated to occur even in a county-based hospital system such as at the LAC + USC Medical Center where charges are based on a flat rate, employees receive no financial compensation based on billing and health care providers are blinded to patient insurance status during their initial evaluation, work-up, and management. ${ }^{16} \mathrm{~A}$ recent study from Temple University specifically looking at penetrating trauma outcomes demonstrated that uninsured patients have a lesser duration of stay and decreased placement into a rehabilitation facility. ${ }^{17}$

The present study has looked beyond the simple presence of health insurance as an outcome predictor for mortality after trauma. Trauma care remains one of the most protocolized and standardized systems of care with management pathways clearly outlined in the Advanced Trauma Life Support manual sponsored by the American College of Surgeons; and, yet, patients of lower socioeconomic status were more likely to have worse outcomes. Overall, they were more likely to have comorbidities despite being younger, were more often uninsured, and were more likely to constitute ethnical minorities in the state of Arizona. After adjustments for these differences, when outcomes were analyzed, low-income patients had higher adjusted mortality risk. When subgroup analyses were performed, according to insurance status, for example, the impact of $\mathrm{MHI}$ on mortality was still demonstrated. For those who sustained penetrating trauma, mortality rates were $6.7 \%$ for the lowest $\mathrm{MHI}, 5.8 \%$ for low, 3.4\% for high, and 2.6\% for the highest $\mathrm{MHI}$ (Adj. $p$ <0.001). MHI was identified as one of the independent predictors of mortality along with age and gender in a stepwise logistic regression analysis.

MHI may affect mortality by several mechanisms because the ability to afford for healthcare directly impacts multiple stages in the process of care. Patients of lower socioeconomic status may experience delays in triaging and transferring to a higher level of care. ${ }^{14}$ Other factors such as living conditions, chronic health issues, ethnic disparities, nutritional deficiencies, substance abuse, violent crime, communication barriers, and educational background are also directly correlated with socioeconomic status. As a result, trauma outcomes may worsen.

Despite being one of the largest studies to date, our study has significant limitations including its retrospective design and inability to control for all previously mentioned factors that may impact survival in this study population. This study included patients stratified according to $\mathrm{MHI}$ in the state of Arizona and may not be representative of the entire United States. A study by Rhee et al. looking at payer status on the utilization of hospital resources among motor-vehicle-related trauma patients at Harborview Medical Center in Seattle failure to demonstrate any discrepancies in disposition, length of stay, or mortality among different payer status. ${ }^{12}$ In addition, we were unable to extract the causes of death. This would have allowed us to examine those considered preventable or potentially preventable as well as to examine those associated with negligence.

In summary, low-income patients have higher adjusted mortality rate after trauma. The evidence continues to point that to address outcome disparities in healthcare, socioeconomic disparities must be ameliorated. Further exploration of these results is warranted.

\section{References}

1. Centers for Disease Control and Prevention. Fast Stats: Death and Mortality. Available at: http://www.cdc.gov/nchs/fastats/deaths.htm. Accessed February 17, 2013.

2. Bolorunduro $\mathrm{OB}$, Haider $\mathrm{AH}$, et al. Disparities in trauma care: are fewer diagnostic tests conducted for uninsured patients with pelvic fracture? Am J Surg 2013;205(4):365-370. DOI: 10.1016/ j.amjsurg.2012.10.026.

3. Coburn N, Fulton J, et al. Treatment variation by insurance status for breast cancer patients. Breast J 2008;14:128-134. DOI: 10.1111/j.15244741.2007.00542.x. 
4. Cram $\mathrm{P}, \mathrm{Pham} \mathrm{HH}$, et al. Insurance status of patients admitted to specialty cardiac and competing general hospitals: are accusations of cherry picking justified? Med Care 2008;46:467-475. DOI: 10.1097/ MLR.0b013e31816c43d9.

5. de Bosset V, Atashili J, et al. Health insurance-related disparities in colorectal cancer screening in Virginia. Cancer Epidemiol Biomarkers Prev 2008;17:834-837. DOI: 10.1158/1055-9965.EPI-07-2760.

6. Englum BR, Villegas $C$, et al. Racial, ethnic, and insurance status disparities in use of posthospitalization care after trauma. J Am Coll Surg 2011;213:699-708. DOI: 10.1016/j.jamcollsurg.2011. 08.017.

7. Franks $P, C$ lancy $C M$, et al. Health insurance and mortality. Evidence from a national cohort. JAMA 1993;270:737-741. DOI: 10.1001/ jama.1993.03510060083037.

8. Greene WR, Oyetunji TA, et al. Insurance status is a potent predictor of outcomes in both blunt and penetrating trauma. Am J Surg 2010;199:554-557. DOI: 10.1016/j.amjsurg.2009.11.005.

9. Haas JS, Goldman L. Acutely injured patients with trauma in Massachusetts: differences in care and mortality, by insurance status. Am J Public Health 1994;84:1605-1608. DOI: 10.2105/AJPH.84. 10.1605.

10. Haider $\mathrm{AH}, \mathrm{Chang} \mathrm{DC}$, et al. Race and insurance status as risk factors for trauma mortality. Arch Surg 2008;143:945-949. DOI: 10.1001/ archsurg.143.10.945.

11. Nirula R, Nirula G, et al. Inequity of rehabilitation services after traumatic injury. J Trauma 2009;66:255-259. DOI: 10.1097/ TA.0b013e31815ede46.
12. Rhee PM, Grossman D, et al. The effect of payer status on utilization of hospital resources in trauma care. Arch Surg 1997;132:399-404. DOI: 10.1001/archsurg.1997.01430280073010.

13. Rosen H, Saleh F, et al. Downwardly mobile: the accidental cost of being uninsured. Arch Surg 2009;144:1006-1011. DOI: 10.1001/ archsurg.2009.195.

14. Sabharwal S, Zhao C, et al. Pediatric orthopaedic patients presenting to a university emergency department after visiting another emergency department: demographics and health insurance status. J Pediatr Orthop 2007;27:690-694. DOI: 10.1097/BPO.0b013e3181425653.

15. Sacks GD, Hill C, et al. Insurance status and hospital discharge disposition after trauma: inequities in access to postacute care. J Trauma 2011;71:1011-1015. DOI: 10.1097/TA.0b013e3182092c27.

16. Salim A, Ottochian $M$, et al. Does insurance status matter at a public, level I trauma center? J Trauma 2010;68:211-216. DOI: 10.1097/ TA.0b013e3181a0e659.

17. Taghavi S, Jayarajan SN, et al. Does payer status matter in predicting penetrating trauma outcomes? Surgery 2012;152:227-231. DOI: 10.1016/j.surg.2012.05.039.

18. Weygandt PL, Losonczy LI, et al. Disparities in mortality after blunt injury: does insurance type matter? J Surg Res 2012;177:288-294. DOI: 10.1016/j.jss.2012.07.003.

19. Federal Reserve Bank of San Francisco. 2006. Available at: http://www. frbsf.org/news/speeches/2006/1106.html. Accessed February 17, 2013.

20. United States Census Bureau. Income, Poverty and Health Insurance coverage in the United States. Available at: http://www.census.gov/ prod/2011pubs/p60-239.pdf. Accessed February 17, 2013. 